\title{
The Great Gas Bubble Prick't; or, Computers Revealed -by a Gentleman of Quality ${ }^{1}$
}

In which are Exposed the delicious Delusions of those will-o-the-wisps; the Echoes in computerization of Phrenology, Haruspication, and other discredited Ancient sciences; and the moral and Mental decline of our Profession.

"If it costs you twenty-five percent more, will you stop it?"

"No."

"Why not?"

"Because we believe that sooner or later all libraries will automate." -From a real-life, absurd conversation.

O N AN EVALUATION VISIT LAST SPRING to a small college (collection 175,000 volumes, peak daily circulation 700), I found the library automating its circulation records, an action tantamount to renting a Boeing 747 to deliver a bonbon across town. Everyone felt great about it; it was a Good Thing! In a college sorely pressed for funds, wasting this amount of money was actually a serious crime against the common weal.

This situation nicely characterizes the fatuousness of one of the most curious periods in our nation's history-the period that began with a rebound off Sputnik, which seemed for a moment to snatch a tip from our crown of world leadership, to strip us of our masculinity, as it were. In this period, which has now passed its peak, money meant nothing, the world of formal education was endowed with magical properties, and technology became an unquestioned God (If we can put a man on the moon we can .... ). This decade boasted of its technical potency with the false bra- vado of a male virgin, and if the moon rocket in the Sea of Tranquillity was its sexual symbol, the computer, choked in its navel cord of programs, was its abortion.

This fact has yet to be generally absorbed. It has already become painfully clear that technology is a two-edged sword of Damocles. Grave doubt has been raised that the computer has done even major industries much good. ${ }^{2}$ But, oblivious to the signs of change, librarians are proceeding in a kind of stunned momentum like a poleaxed steer, because the computer industry and its public handmaidens have polluted our intellects. In one of the most massive public manipulations in history, the computer has been joined to Motherhood, the True, the Good, and the Beautiful. Operational considerations have been stripped to a stark choice between "the old hand-method" (ugh!) and THE COMPUTER. The effect has been to obscure a whole range of machine and machine-manual alternatives. ${ }^{3}$ 
Technology has been set back many years and intelligence has been uprooted. Any fool who does anything with a computer for any reason (we all know at least one) is automatically a genius; anyone who does not is the last of the dinosaurs.

During a period of study sponsored by a Council on Library Resources (CLR) fellowship which allowed me to study problems in ten major research libraries last spring, my observations convinced me that the high costs of computerization make it unfeasible for library operations and that it will become increasingly expensive in the future. ${ }^{4}$ The computer feeds on libraries. We actually devote large amounts of talent and massive amounts of money (perhaps $\$ 25$ million dollars a year in academic libraries alone) to diminish collections and reduce services, exactly at a time when libraries are starved for both, by channeling money into extravagant computerization projects which have little or no library benefits. While my original expectations were entirely in the opposite direction, after talking at length with some of the finest computer experts in the library world and probing the thinking behind more than forty computerized library operations, it became clear that the application of computers to library processes is a disaster, and that no one is willing to admit it.

The reasons for its adoption are governed by a range of irresponsible, irrational, and totally unmanaged factors, both within the library and in the university, that cannot fail to disgust anyone seriously concerned about the academic world. This article intends to analyze how we learn to stop thinking and love the machine, and to make possible the return of intellect and managerial methods to an area of library practice from which both have been driven.

\section{The Rough Beast With Three Breasts}

Unlike most other machines, the computer is not subject to reasonable surveillance at any level of operation. ${ }^{5}$ A college president or the manager of industrial research cannot judge with any reasonable degree of accuracy how much computer capacity is required for his needs, nor can his subordinates. This means that basically he must accept his computer configuration on faith and on the urgings of computer industry representatives.

This condition in which the computer wanders free from quality checks extends right down the line of a computer operation to the head of programming, who cannot judge with any degree of precision the quality of the programs written for him. ${ }^{6}$ He can tell whether they run (indeed, the principal struggle is to get them to run trouble-free at all), but he cannot tell how they rate in comparison with the range of other alternatives. This free-form condition of control, which is inherent in the occult nature of the computer, accounts for the great range of loose work and random performance observable in computer operations.

Moreover, a computer operation is incapable of becoming stabilized on its own terms. No matter what level of performance is achieved, if a later generation computer is marketed, it is necessary to shift as soon as possible to the new generation, with all the agonies, dislocations, and setbacks involved in the change, and with no assurance that the same level of results can be achieved. There is no choice of remaining as you are if reasonably satisfied with your results because it is extremely difficult to recruit a systems and programming staff (doubly difficult for libraries, which lack the glamor and loose money that have characterized industry until recently). A good staff will abandon a superseded model computer, 
since to remain would make them professionally obsolescent.

These two floating conditions make computer operations basically uncontrollable. In managerial terms, these facts alone would argue for discarding out of hand any other machine in existence, until it was amenable to quality control. But we have been conditioned to suspend completely the requirements that apply to all other equipment, and automatically accept the computer as Good, without questioning. We accept the computer as the pot of gold at the end of the rainbow, the touchstone that turns dross into gold. Glittering with spangles, draped seductively in the fluff of unreason, it really has sex appeal, and who applies reason while gulping the lures of a floozie like Myra Breckenridge? ${ }^{7}$

\section{The New Bloomusalem}

When Leopold Bloom, Joyce's common man in Ulysses, proclaims, while playing God in an hallucination, "the golden city which is to be," thirty-two workmen wearing rosettes construct "The New Bloomusalem," a megastructure in the shape of a huge pork kidney. Something like this debased miracle happened in library computerization in the decade of the sixties, when computers rode tall in the industrial saddle and librarians flung themselves at the horse's tail. During that decade, our large problems were operational (whereas now they are desperately financial) and we looked for a panacea. Noting us sniffing around the computer, the industry perked up and assured us they were the answer.

A kind of syllogistic thinking followed -we have problems; the computer says it can solve them; therefore, using the computer solves our problems. ${ }^{8}$ It's all simple enough and clear enough if you just have Faith, and of course, Reason is the enemy of Faith; in fact, it gets in the way of certainty. In our awe at the wonders of technology, we forgot the deadly threat of Dr. Strangelove's mechanical hand. Like lemmings moving toward the sea, we surged to get with it, became scientists, became industrialists, and practiced the best that was known and felt in the business world. ${ }^{9}$ In the whole range of the academic world, we forgot one of our traditional functionsto suspect the beguilement and evanescence of the moment and "to keep clean our sense of difference between the temporarily and the permanently significant."10 In short, we embraced with fervor all the sins of the commercial world. Now, look at the commercial world and at the academic world and wonder how it is that student rebels connect the two.

The fascination of the computer, like that of a hooded cobra, lies in its exotic beauty, which fixes its victim for the spurt of poison. On the surface it seems to have many answers. It looks effortless, is pleasantly mysterious, it makes pleasing sounds, it promises great speed, and it has a reputation for performing miracles. Despite its beginnings in 1942 (long before Xerox), it is considered the latest technological development. So we got with the new and the technologically best by adopting the computer. We did so to solve simple and clearly defined problems-to save staff (or substitute for staff that we couldn't hire), to speed processing, and to save money. Information retrieval was seen in the distant mist, but these were the clear and central targets.

But when we used the computer, it didn't save staff, and it didn't speed processing, and it cost a great deal more to do the same things we were doing by hand. Our reaction was to computerize more. Although we lost money on every operation we computerized, the theory grew that if you knit enough losses together, obviously you would save mon- 
ey. In Orwellian doublethink, if you waste money in an attempt to save it, save better by wasting more. We still didn't save staff, and we didn't speed processing, and it cost us even more money. Our latest answer is to use newer and bigger and more expensive computers; it still is not saving us staff or speeding processing, and we are now spending extravagant amounts of money. We bombed library problems with the computer, and the strategy didn't work. So we bombed even more problems with the computer and it still didn't work, so we are bombing even more.

\section{Just Like General Motors}

At this point, the third strange fact about the computer becomes clear. It is a half-baked machine. Every other kind of equipment we use is bought for specific purposes, to perform defined tasks, at a known cost. Even highly automated equipment like the MT/ST comes with a simple program to perform known tasks after a modicum of training. A wholly baked computer, nicely browned, would be ordered to specifications, and would come ready to dust off, to insert the program provided by the manufacturer to do what we wanted to be done, and to begin our computerized operation. Only under such conditions would we consider any other machine. But we have been brainwashed not to apply the same reasonable standards to the computer. The cobra has us hypnotized.

When it is dumped on your dock, it can do nothing for you; like, Ford delivers you a Continental and deposits it in your yard. You leap with joy and shout to the neighbors who come to admire. You puff with pride, as we do for computers. "Let's go for a ride," they say. Somewhat sheepishly, you explain that it is a new proto-electric Continental, with a wonderful fume-free motor, but that there is no battery known strong enough to power it. When they say,
"Why did you buy it?" do you reply, "Oh, I'll do my own Research and Development to produce the battery"?

Such an answer would be insane, but this is exactly what we do for computers. ${ }^{11}$ We assume the responsibility, the elaborate costs, and the human agonies involved in programming to make the machine do what we knew we wanted it to do before we bought it. In one project now underway, it will take a staff of ten, three years to make anything happen. Libraries really are getting important when they can play junior GM (without GM's budget) and launch amateur research and development operations, which is what programming really consists of. No matter how good our systems staff, such research and development must remain amateur. We don't know enough about technology even to know which field we should work in to solve our problems, let alone which machine we should encourage. We haven't the meagerest grasp of the perspective required by industrial $R$ \& D. But we have enthusiasm, we have suspended our brains, and we've come to love the computer.

We spend millions making the computer work for library activities, with a guarantee that it will produce a built-in deficit and with only a vague chance that it will improve anything. We simply can't wait for the finished machine, for the one that really works, the one which when it comes will make computers useless. We must develop it ourselves, even if we have to sell our libraries (which we are doing) to do so.

\section{How We Are Covered With Locusts and How the Invasion Began}

How did we get into this mess? There are precedents in human history. The mountebank pulls up at the crossroads and the yokels throng the tailgate to buy snake-oil guaranteed to cure any dis- 
order of libraries. Gullibility accounts for part of it; pressures account for the rest. The physical scientists and mathematicians brought the computer on campus for its computational facility. ${ }^{12}$ Engineering, which quickly was seized by electronics specialists, burgeoned later. From these three groups came large demands for computer time in the universities. Administrators, naive and uninformed, began pressures to have all the computer time on campus used because of its heavy cost. They began by offering "free" computer time (an interesting concept at current prices) to any department that would use it. This free offer sprang from the prestige value inherent in using the computer (the industry did supply the prestige) and from a conviction on the part of administrators (also supplied by the industry) that use of the computer saved money for any operation it touched.

As this free time was used, the demand for computer time overran that available, and bigger, better, and much more expensive computers were brought on campus. With even greater increases in expense, administrative pressure (as brainless as all other pressures involved in computerization) intensified, and in some instances became downright nasty to departments that dragged their feet either through lethargy or knowledge. They were joined by the computer engineering faculty, which in recent INTREXed years, has become self-deluded to an extreme degree. ${ }^{13}$

Librarians, most of whom are humanistically trained, are especially sensitive to accusations by technologists and administrators of refusing the best that is known to business and technology. Even when they know better, consistent pressures unsettle their confidence. To cool the hot breath of the president's office, one university made a list of special materials by computer when they knew in advance they could do it considerably cheaper by more than one noncomputer method. To appease the demands of a renowned and totally impractical engineer, one university went to a computerized circulation system as the least wasteful operation they could run on the computer. The fatuous self-confidence of computer experts is considerably jolted when they have to cope with the demands of library operations, which are far more complex than anything else they tackle in terms of their machine. But so long as they can throw stones from a comfortable theoretical distance their pressures are compelling indeed.

\section{The Electronic Calf}

In a time of waning personal confidence, it takes a very strong man to stand up to a university president and tell him he's wrong when he is convinced by technologists that inertia springs from ignorance. There are only a few men left these days. Therefore, with the prod in our rear, or approaching, we adapted to the new campus ecology, now polluted by technologists. Although some librarians seized the computer for its public relations value (Look, mommy: no catalogers!), the more sober members of the fraternity went along with a better conscience by adopting a mystique about the computer that grew partly outside and partly inside librarianship.

This mystique generated, and in turn was generated by, a group of librarians whose livelihood depended on the computer, and whose reason for being depended largely on their ability to believe the computer industry's claims laid out before them. The emergence of this Faith and the band of True Believers have been responsible for the rapidity with which we have gotten into computerization despite all evidence that the fantastic claims for the computer are completely false. This group of 
the faithful was abetted by enormous sums of government and foundation money that flowed, like Niagaras of champagne (Lucius Beebe's phrase), into computerized projects for a fiveyear period. With this amplitude of fuel, these neo-Zoroastrians began to burn up the world.

\section{The Revelation}

Blazoned across the dark benighted sky of conventional librarianship were the following Truths:

The First Truth-Come to the computer all ye who are heavy laden and It will make everything effortless. ${ }^{14}$

The Facts-The computer has involved librarians in greater and more prolonged agonies than anything in recent history short of the Florence flood. Agonies of campus politics (flipped from computer to computer), agonies of financing ( since the golden angels have gone), agonies of programming, patching programs, reprogramming, redebugging programs, agonies of lengthy machine breakdowns, agonies of deception by computer experts (both in industry and in other campus units) have left deep scars on every library computer expert I have known. ${ }^{15}$ While I was on campus one university was executing the second major cutback of computer capacity within three years, each causing major upheavals and changes in staffs and procedures and the bitterest kind of infighting to control the nature of the computer configuration. The most efficient road to ulcers on a college campus, short of the president's office, is through library computerization.

The Second Truth-Thou shalt do everything with the speed of light, if thou butst computerize.

The Facts-Response time of computers, which is incredibly fast (as fast as the movement of an electron), is not to be confused with the response time of computerized processes. ${ }^{16}$ It is common knowledge that computerized class schedules take weeks longer to produce than the old hand method. In librarianship, these are some of the commonplace delays found strewn all along the trail: Circulation, a delay of one day in the ability of the circulation file to account for the location of a charged book (in one case, the costs of paper led to updating the file only once every three days). On-line circulation, the alternative to batching, is so astronomically expensive that anyone who adopts it should be summarily condemned as a public malefactor. Acquisitions-consistently slower in placing orders. Acquisitions was so slow the spring that I was on campus that, in one case, 20 percent of their periodical subscriptions were cancelled due to slow placement of orders. Book catalogs-longer and longer delays in cumulations because of the costs involved. In the case of one university, an operation highly touted while in action had left a liberal arts college with its book catalog in four (repeat, four) parts. They were at the point of doing what they were sure would be, forever, their last total cumulation because of its cost, while their future lies in a book catalog always in two and three parts. They would like to go to a card catalog, but at 100,000 volumes, cannot afford to. One circulation operation, where the students were cleared faster than previously at the charge-out point, claimed this advantage, without noting that the new system involved the use of book cards in lieu of user-written cards, and that the computer charging console takes longer than most simple charging machines.

The Third Truth-The computer will save you money.

The Facts-Computer experts laughed when I suggested economy as a motive for adopting the computer. No one claimed to have saved any money doing 
anything by computer, and although the analysis of computer costs is, to be charitable, hair-raisingly casual, estimates of costs of doing by computer exactly the same things that had previously been done manually were extremely high (in one case, five times the cost). We now know there is no clear evidence that the computer has saved industry money "even in routine clerical operations." 17

The Fourth Truth-Well, anyway, once you have done it, thou shalt have economies in future programming by having programs convertible to later generation computers.

The Facts-Absolutely false! About half of the third-generation computers in major industries are in an emulation mode that makes them perform as second-generation computers because industry, having been hooked on the enormous programming costs for the second generation, is unwilling to absorb even higher costs to program for the third generation, which leads to an interesting view of our economy (like our libraries), buying the latest to get with it to avoid losing face. ${ }^{18}$

The Fifth Truth-Well, anyway, once someone has done it, programs can be converted from location to location, so you save the expense of programming for yourself.

The Facts-This initially was one of the most appealing lures of the computer industry. A few years ago, in a correspondence with Robert Hayes of the University of California, I asked why we all had to make the computer repeat on machine the motions we were doing by hand. Since we all need about the same end products at the same key points in a serials operation, why couldn't one library program it and present the program in modules, each of which could accomplish one thing, for us to choose those we preferred? At length, in a series of letters, I learned the elaborate and complex reasons why this could not be done. All the library computerators I questioned agree that transferability of programs is completely unfeasible at present and in the future. ${ }^{19}$

The Sixth Truth-Thou shalt have cheap computerization by sharing computers with others.

The Facts-This, again, was one of the bright promises laid out by the computer industry, but the deeper we get into library computerization, the more evident it becomes that sharing computers to reduce costs is a chimera. Yet within the month, an eminent professor of industrial management who read my CLR report trotted out the old turkey that, with remote access consoles, sharing computers would soon make them economical.

The Seventh Truth-Thou shalt save money as you multiply the separate operations that you computerize if you combine them by a systems approach.

The Facts-Though a common belief among the aborigines of Computeria and sustained by a well-developed theology, there is no evidence whatsoever to support this belief. ${ }^{20}$

The Eighth Truth-Thou shalt have greater service for the public by computerizing library operations.

The Facts-Most of the libraries computerized seem to have no interest in improving service, as we can see from such things as their average line-staff salaries (mostly at the peonage level), the size of their cataloging backlog (in one case about 300,000 volumes), and the staffing of their campus branch libraries (about half of the staff needed). Money wasted in computerization could greatly improve service if applied to these areas. Also, processes that delay placement of orders, delay accountability of circulation records, and split the card catalog in multiple parts would not seem to be aimed directly at improving service to the public. 


\section{The Credo}

Throughout the land, the priesthood, with no exception, recited to me "The Credo of Automatic Automators":

I believe in the increasing cost of labor and the decreasing cost of computers.

I believe that in ten years (the time span was standardized) the cost curves will cross in favor of computers.

I believe that even if it isn't cheaper, the by-products of computerization make it worthwhile.

Since my pilgrimage, I have had the same Credo recited by others who were not specifically computerators, so there must be international specifications for its writing. It requires some examination.

First: there really is no "decreasing cost of computers." It is true that, on paper, the unit rental cost of new generations of computers decreases, but in sounding out what actually happens in practical applications, it is evident that the cost of applying the machines has increased due to various factors, one being the difficulty of keeping the computer fed without interruption. ${ }^{21}$ But the central fact is that the overwhelming costs in computerization are labor costs (machine costs run about 20 percent of the total), and the salaries of systems analysts and programmers go up even faster than library staff salaries. Even after initial development costs are absorbed, the repeated costs of reprogramming and program adjustment are very high. Since the costs of computerized library operations are far higher than manual alternatives now, and the costs of computer labor are increasing faster than library labor costs, computerization will become increasingly expensive in the future.

Second: we are willing to accept any machine that will save us money at any time, ${ }^{22}$ but if that time is ten years from now, then 1981 is the time to adopt the machine. What kind of folly wastes money for ten years on a machine that it hopes will eventually save money? Within ten years new machines, now unseen, will emerge in competition with the computer.

Third: the matter of by-products is the smelliest red herring of all those dragged across our path by computerators. The word is invoked with a kind of awe, as though it descends from heaven to banish all the disabilities of the computer. As Melcher put it: "we find ourselves invited to applaud computer applications that are somewhat in a class with the dog who played the violinnot that it was done well, but rather than it was done at all." ${ }^{23}$ I keep having draped before me as accomplishments by-products that either are of no use whatsoever for a library operation, or that have a very low incidence of use, or that can easily be done by hand or by other machines faster and at a lower cost. The questions that are ignored must be asked-what by-products are worthwhile, for what library purposes, at what costs, and for what incidence of use? In sum, I find the Credo, like all matters of dogma, an excuse for suspending the intellect on the part of librarians and managers.

\section{The Miracles}

At the very peak of library computerization we are breeding a group of extremely able librarians, whose otherwise fine intelligence is completely blown when they evaluate their machine. They analyze their daily operations with command and critical brilliance, but when they talk about their future, like a sun-crazed prospector dribbling fool's gold through his fingers, a dull film covers their eyes, and they babble about miracles to come that are just around the corner, with not a shred of evidence to support their beliefs. Their 
faith is the exact equivalent of a witch's faith in flying ointment. Unfortunately, we have long passed the stage in which we could run a library from a broomstick.

Nevertheless, one can respect the priesthood. It's the acolytes, and at their fringe, the sycophants that make us feel unclean. Here we are in a range of oneupmanship and pretentiousness straight from Madison Avenue. ${ }^{24}$ Responses to questionnaires about computerized operations produce amazing answers, if you know what is really going on in libraries. If someone lays down a transistor on a typewriter, the department is likely to respond that it has automated. The computer is used to cover up weaknesses as cowdung was to plaster frontier $\log$ cabins. If catalogers are low producers, if circulation is in chaos, the tendency is to computerize instead of reviewing or revising operations, both of which require thinking.

So, the rules of thumb are clear-if you start a library from scratch, computerize and you're fifty years old. ${ }^{25}$ If you're upgrading an $\mathrm{Ag}$ college, the computer will liberalize cows. If you're a frustrated junior college, computerize and it makes you Ph.D. If your faculty is lousy, computerize and you'll be Harvard. If you're bush league, computerize and you'll win the Series. If you're stupid, computerize and you'll feel great. Instant achievement by machine and cheap attempts to invoke a false sheen of glory have replaced an intelligent confrontation of the problems in a large number of weak libraries.

\section{Run, RabBit, Run}

In view of the irrationality of the forces that led to library computerization, and the subsequent aggravation of this situation by self-seekers, it should come as no surprise that managerial practice has entirely left this field. ${ }^{26}$ Of the forty-odd computer projects re- viewed on my leave in ten major libraries, not one was begun on the basis of a managerial decision, after carefully reviewing and costing the operation to be converted, costing other machine or machine-manual alternatives (which were obviously available for many of them), or carefully projecting the costs of the computer operation after development costs (which one should be willing to absorb if retrievable over a period of time). Since most of the projects were doing only what had been done manually, price should have been the major factor in making this decision, yet very little cost analysis was applied, although all the libraries were hard pressed for funds. No computerators were surprised when I reported lack of managerial decisions; it was taken for granted that there were none in computerization. Like concupiscence, the desire to computerize simply must be satisfied no matter what the cost, and this at a time when most universities and libraries are bankrupt and facing an even bleaker financial future.

\section{Downhill All the Way}

My discussions of this problem have produced a number of oppositions over the past few months, the most interesting of which is the concept of comparative incompetence advanced by a friend of mine. It makes no difference, the argument goes, that no careful cost comparisons precede computerization, because most librarians do not analyze costs before making other changes in libraries. The premise, I think, is false; but even if it were true, it is almost impossible to make even approximately as large a commitment in any other way in a library as that involved in computerization, where a quarter of a million dollars is meager.

More harrowing than the enormous costs is the fact that a computerized 
system is virtually irreversible, the fourth distinctive disability of this machine. ${ }^{27}$ Once you begin a systems approach to computerizing operations, you are hung by the gills on the computer industry's fishstringer for good. Once applied, the computer acts as a powerful agent against change. The dynamics here are interesting. One library began to computerize by hiring a systems librarian who hired one programmer when they began to convert their circulation operation. Two years later, when the agonies of this conversion had subsided (and the circulation costs were fantastically more expensive than the manual system, and they were cumulating circulation records only every three days), the staff of this department was five, and, having been blooded, was eager to begin computerizing another operation. Even if you could prove that further computerization was diabolically evil, you still could not stop this momentum.

In addition, once computerization begins, the campus pressures on the library to get with it have been assuaged, the operation has been tapped for its public relations value, and personal and institutional egos are heavily invested in ploughing ahead to disaster. This is especially true if the computer project is the librarian's baby. One highly touted serials project began on "free" computer time, then later was charged for the campus computer costs (which hurt, but were not disabling). When the campus changed its computer and this operation had to use commercial firms for the computer configuration necessary to run its program, the cost more than doubled previous costs. After reprogramming for over a year, this serials operation is still processed partly off and partly on campus: It is known as a disaster area among computer experts, but this librarian stated recently that he thought it had done his library a lot of good.
Inertia also results from sheer moral exhaustion. The prolonged agonies inflicted on any sane person during the process of converting to computerization push him to the extremes of human endurance. After all the bugs are exterminated and the system is running, it is virtually impossible for a survivor of the process to summon up the moral strength to rethink, reorganize, redevise processes, and restaff. In one case, where superficial cost comparisons convinced an acquistions operation it was saving money, more sober thought made clear that it was losing money and taking longer by computer. But the department head was very indignant when I proposed that they could return to their former system-“After going through all of that?" Another department head refused even to reconsider and attempt costs comparisons when, after three years, her computer system was finally working.

Then, of course, there are enormous inflexibilities imposed against change by finances. Development costs in one case seem to be running over a million and a half dollars. You can be sure that it will take quite a jolt to make a library abandon that large an investment. In other instances, the costs of changing to an alternative system require large amounts of money not in hand, as in the college with the four-part book catalog that would prefer a card catalog. Until the totality of waste in operating by computer becomes so large that the figure really appalls, the library is not likely to make the sensible move, especially in the face of the beneficent connotation that (in libraries, at least) is still attached to the computer.

\section{The Brave New World}

Anyone who computerizes at this point in time is hitching his wagon to a falling star. The honeymoon is over, if 
our seduction by the computer can be so termed. We have been sucked in by one of the most potent information control powers in recent history. Computerizing library operations at present and projected costs, and with foreseeable results, is intellectually and fiscally irresponsible and managerially incompetent. The proper answer to idiots who beamingly dangle their computerized projects for our admiration is, "Why don't you do something useful, instead."

The shrinking financial support of the academic world will drive us to sense even against our will. On the campus where I found forty-nine computers (four of them IBM 360's; one, the largest capacity known), the president gave the bloodiest state-of-the-university speech to date-dropping three academic programs, cutting back the current budget forthwith a million dollars, forecasting a further rollback of 3.5 million over the next three years, and even this predicated on unusual success in fund raising.

This is no temporary condition tied to the recession. More than two years ago, it was apparent that the public had become disillusioned with technology and education. They expected miracles of both; yet it is clear that each is the answer to only a part of our national problems. Public support for technology, a keystone in education's expansion, will continue to decline. Alumni disillu- sionment with campus products has seriously diminished alumni support. Foundations have been turning from the academy to other social agencies. The production of bachelor's, master's, and doctorate degrees has overrun the market for their products. Elementary and secondary school populations continue to decline. Education has costed itself out of sight, either in tuition costs or in the total costs of public institutions. All of these factors guarantee us future curtailment of programs in higher education and a continual decline in financial support, except for those programs immediately responsive to immediate problems that enjoy public favor. Make no mistake, we are about to shake out the men from the boys, and the future in libraries (as in other areas of university services) lies with the managers, who can make the most out of every cent available. The computer is the machine that evaporates money the fastest. ${ }^{28}$

In sum, our experience with the computer in library operations has been one more replay of The Emperor's New Clothes, and what we were led to believe were distant mountains laden with gold, available merely by boring a drift in the slope, turn out, upon close inspection, to be the hairy buttocks of the well-fed computer industry. And from such a source we have gotten exactly what we should expect.

\section{REFERENCES}

1. Ellsworth Mason, Director of Library Services, Hofstra University.

2. Quite obviously, this kind of view is not encouraged by industry, but when it emerges, it is extremely revealing. In "Computers Can't Solve Everything," Fortune (Oct. 1969, p.126-29+, Tom Alexander reports the principal findings of a highly disenchanting survey by the Research Institute of America of computerization in 2,500 leading U.S. industrial companies. In "Automation: Rosy Prospects and Cold
Facts," Library Journal (15 March 1968), p.1105-09, Daniel Melcher, president of the R. R. Bowker Company, indicates in detail that, although computerization is costing the publishing industry more than former processes, its effect has been to diminish performance.

Alexander contends: "But now, after buying or leasing some 60,000 computers during the past fifteen years, businessmen are less and less able to state with assurance 
that it's all worth it." (p.126) "As the Research Institute of America survey revealed, most companies are unsure that there is a payoff from computers even in supposedly routine operations." (p.128) "Relatively few companies have yet succeeded in devising nonclerical applications for the computer (because) programming and equipment costs are so high." (p.127)

Melcher contends: "To be candid about it, however, I think we could have done all this if anybody had wanted it, even before the invention of the computer." (p.1109) "Anything can be done (by computer), I guess, but that isn't the issue. What matters is whether anyone in his right mind would choose that way of doing it." (p.1109) "They all hope for tangible economies in the future-though it is a bit puzzling to note that the $\$ 5$ million companies seem to expect those economies when they reach $\$ 10$ million, and the $\$ 10$ million companies think there might be economies when they reach $\$ 20$ million, etc." (p.1105) "Computers have unmistakably lengthened the time it takes to fill an order, and have made it almost impossible to understand a royalty statement or get an intelligent answer to a complaint or a query." (p.1105) "The near-term result often seems to be that information formerly available by means of a phone call to the order department is reported as unknowable until the computer makes its next periodic report." (p.1106) "Batch processing ... can delay your orders, delay your deliveries, delay your payments, and cut you off from ready access to your own data." (p.1109)

Victor Strauss, a consultant for printing management and contributing editor of Publisher's Weekly, states: "The computerization offered neither price advantages nor delivery advantages to book publishers." "The New Composition Technology: Promises and Realities," Publishers' Weekly 195:62 (5 May 1969).

3. Circulation is one operation in which librarians seem to see nothing between a manual and a computerized system, whereas in reality, a large range of alternatives exists. See also Melcher, p.1106: "Other machines also cost less or do more. The cost of offset printing plates drops from $\$ 1.50$ a page to $\$ 1$ a page to ten cents a page, even to five cents a page-in an almost unbelievable series of technical breakthroughs."
4. "The old idea that an automated system could be operated at a new lower cost than a manual system is dead, indeed." [Allen Veaner, "The Application of Computers to Library Technical Processing," CRL 31:36 (Jan. 1970).]

"Wishful thinking about present and future costs may give us librarians a black eye with the very administrators who are urging us to 'get with computers.", [William Locke, "Computer Costs for Large Libraries,” Datamation (Feb. 1970), p.74.]

"I talked to one wholesaler who had really made his automation work, but who had wound up with costs a good deal higher than a competitor's. I asked whether he really thought he could get his costs down. He said: 'No, but I think the other fellow's costs will rise-he's automating, too.'” (Melcher, p.1107)

See details of the high costs of computers in educational processes in Anthony G. Oettinger (of the Harvard University Program on Technology and Society), Run, Computer, Run (Cambridge, Mass.: Harvard University Press, 1969), p.189-200. This is the most penetrating analysis to date of the application of various technologies that are "force-fed, oversold, and prematurely applied." See also the frank statement on the costs of computers, including limitations on the cost reductions possible in the longterm future, in Frederick G. Withington (of Arthur D. Little, Inc.), The Real Computer (Reading, Mass.: Addison-Wesley Publishing Co., 1969), p.37-41.

The literature is riddled with irresponsible accounts of project costs that make no real attempt to include the full range of costs of computerization.

5. This fact was called to my attention by a manager of an aerospace satellite systems division.

6. "Programming is still very much an art and one in which there seem to be no standards of performance." (Alexander, p.171)

7. Just compare. We are lured by the frills of computerization and forget its enormous basic costs. Myra, with her six-foot-seven escort, proposes to forget the six feet and concentrate on the inches. "The glamor, let's face it, is in the computers, but the breakthroughs are elsewhere." (Melcher, p.1107)

8. "They (computers) are creatures of their time, and they come because they are 
needed." (Melcher, p.1106) Melcher makes the common mistake of assuming that, because we needed something to help us in volume operations, the computer is what we needed. I contend that it is not. He states later, "It must be noted, however, that as yet the utilization of the computer to meet those changing needs has been massively disappointing." (p.1107)

9. "The service bureau put out cards through its computer instead of through the far simpler card lister formerly used. The result was no different, and they charged us three times as much-but it made us feel kind of big league." (Melcher, p.1109)

10. A phrase by one of our best poets of the 1930s, now reemerging, Laura Riding.

11. "In effect, each new task for a computer entails the design, development, and fabrication of a unique machine, assembled partly out of the boxful of hardware, partly out of software." (Alexander, p.171)

12. I still accept on faith the remarkable computational facility of the computer, though cautioned by friends in industry that unless the computer is checked at each permutation point in a computation, they cannot be sure that the results are right, because of possible disorders in the machine. Since checking takes too much time, technologists accept the computer's results, fully aware that often they are working with unreliable data!

13. This may have eased somewhat, since the extravagantly financed and well-publicized grunts of INTREX at M.I.T. have brought forth a mouse. The self-delusion of electronics engineers is demonstrated in the fact that, since they have taken over control of the engineering schools, "insignificant" courses, such as Power and Illumination, have been dropped from all of them. Maybe if we don't look, need for such knowledge will go away.

"When the new specialists were asked to understand before they criticized, some of them were outraged. "We should learn from you? You've got to be kidding. Should we, the Knights of Systems Analysis, soil our anointed hands with that old rubbish? Learn about it? We will simply sweep it away in no time with our electronic broom. We'll put you out of business!' " [Victor Strauss, "Betwixt Cup and Lip," Publishers' Weekly (26 Jan. 1970), p.263.]

14. Similarities to Christian doctrine are due to the fact that Computer theology is vaguely Christian in orientation.
15. The most extreme deception encountered involved a campus computer unit which contracted with the central library (apparently to get access to its grant money) to handle a library operation, one of whose basic requirements was the integrity of the information stored in the computer (an IBM 360/67). Months after programming began, the library discovered that the chances of this machine wiping out its storage file are high, a fact known to the experts from the beginning.

16. See Melcher's statements in footnotes two and four.

17. Alexander, p.126.

18. "One knowledgeable consultant estimates that about half the System/360's now installed are still operating in the 'emulation' mode (i.e., are acting as second instead of third generation computers) . . . at least a billion dollars worth of new machine capacity is, in effect, wasted." (Alexander, p.129) If we can brainwash people to be so stupid, why can't we brainwash them to be virtuous?

19. Allen Veaner discusses this problem in full in "Major Decision Points in Library Automation,” CRL 31:308 09 (Sept. 1970).

20. "Within limits, the more of our processes we get computerized, the better chance we have of matching the costs of the manual system." [William Locke, "Computer Costs for Large Libraries," Datamation (Feb. 1970), p.72.] When pursued by mail, Locke admitted that he has no evidence to support this contention.

21. "Despite the fact that, on a capacity basis, the IBM System/360, RCA Spectra 70, and GE 600 series are cheaper to lease or buy, they have been the hardest put to show a demonstrable payoff ... they are too costly to be sitting idle, but they also need more highly qualified-and more highly paid-personnel to operate effectively." (Alexander, p.129)

22. Hofstra is now running final cost estimates on an MT/ST card production system despite warnings against it. But we began with careful cost control of our manual production and will be able to compare costs to decide whether or not to continue.

23. (Melcher, p.1107) His figure, of course, is stolen from Samuel Johnson.

24. "The rules of the computer game are that you talk only about what you are going to do, never about how it turned out. This is a science in which you publish the results of your experiments before you make them." (Melcher, p.1105)

25. For what happens when computerization 
begins with the library, see Dan Mather, "Data Processing in an Academic Library," PNLA Quarterly 32:4-21 (July 1968).

26. "In companies everywhere the reasons for buying computers were not thought out. From the top, the attitude was that you can't let the competition get ahead of you; if they buy computers we've got to buy computers. The result was great euphoria." (Alexander, p.126, quoting a GE internal consultant on computer usage.) "According to the survey, the majority of computer users believe they themselves were too precipitous in acquiring their machines." (Alexander, p.127)

27. "Yet once in the grasp of an automated system, there is no turning back. Entering upon an automated system in any enterprise is practically an irreversible step." [Veaner, "The Application of Computers to Library Technical Processing," CRL 31:37 (Jan. 1970).]

28 . "But do people only want to save money?" plaintively writes a computerator to me. If at no other time, certainly when they are bankrupt. 